\title{
Preventing Catheter-Related Bacteremia with Taurolidine-Citrate Catheter Locks: A Systematic Review and Meta-Analysis
}

\author{
Hongbo Liu ${ }^{a}$ Hongmei Liu ${ }^{c}$ Jing Deng ${ }^{b}$ Lihua Chen ${ }^{a}$ Lu Yuan ${ }^{a}$ Yong Wu \\ ${ }^{a}$ Department of Medicine Clinical Laboratory, The Third Xiangya Hospital, Central South University, and \\ ${ }^{b}$ Department of Epidemiology and Biostatistics, School of Public Health, Central South University, Changsha, and \\ ${ }^{\mathrm{C}}$ Department of Biological Psychiatry, Shanghai Mental Health Center, Shanghai Jiao Tong University School of \\ Medicine, Shanghai, China
}

\section{Key Words}

Intravascular catheters . Catheter-related bacteremia .

Taurolidine-citrate $\cdot$ Heparin $\cdot$ Meta-analysis

\begin{abstract}
Background: Preliminary evidence from some studies suggests that taurolidine-citrate locks decrease catheter-related bacteremia (CRB), which is a major cause of morbidity and mortality in patients using intravascular catheters. No previous study has sought to summarize existing evidence on the use of taurolidine-citrate locks. A systematic review and meta-analysis were undertaken to determine whether taurolidine-citrate was more effective than heparin in the prevention of CRB. Methods: The major English (PubMed, EBSCO, Web of Science and OVID) and Chinese (CBM, CNKI, VIP and Wanfang Data) healthcare databases were searched for randomized controlled trials comparing the efficacy and safety of taurolidine-citrate lock solution (TCLS) and heparin lock solution in the prevention of CRB. Results: Three studies involving 236 patients with a total of 34,984 catheter days were included. The use of TCLS significantly decreased the risk of CRB (relative risk $=0.47,95 \% \mathrm{Cl}$ : $0.25-0.89$ ) and Gramnegative bacterial infection. There was no significant difference in Gram-positive infections and exit-site infections.
\end{abstract}

Conclusions: Catheter locking with TCLS reduced the risk of CRB and Gram-negative bacterial infection. Adverse events include thrombotic events.

(c) 2014 S. Karger AG, Basel

\section{Introduction}

Intravenous access is an essential lifesaving intervention in critically ill adults and children receiving parenteral alimentation, antibiotic therapy, hemodialysis, chemotherapy and hematological malignancies. The major factors limiting the long-term use of central venous catheters are catheter-related infections and poor flow, particularly catheter-related bacteremia (CRB) [1]. The prevention of $\mathrm{CRB}$ remains a significant challenge because of the associated high morbidity and mortality [2]. The incidence rate ranges from 0.34 to $6 \mathrm{CRB}$ episodes per 1,000 catheter days in some studies [3-5], and can reach 10.8 episodes per 1,000 catheter days [6] in others.

Prevention of bacteremia is crucial. A number of strategies to reduce the incidence of CRB have been tried, including the use of strict hygienic measures, antibiotic-impregnated catheters, eradication of Staphylococcus aureus nasal carriage and prophylactic antibiotic ointment on

\section{KARGER}

E-Mail karger@karger.com

www.karger.com/bpu
(C) 2014 S. Karger AG, Basel

0253-5068/14/0373-0179\$39.50/0
Yong $\mathrm{Wu}, \mathrm{PhD}$

Department of Medicine Clinical Laboratory

The Third Xiangya Hospital, Central South University

Changsha 410013 (China)

E-Mail wuyong_xy@163.com 
the exit site [7]. Taurolidine and heparin, which can reduce the incidence of CRB, are often used as a solution to prevent bacteremia in patients who need a central catheter, as with hemodialysis, cancer and parenteral nutrition, as well as in the ICU [8-11]. It has been suggested that heparin, the most common catheter lock in clinical practice, may be abandoned because spilling into the bloodstream may expose patients to the risk of bleeding [12]. A promising approach is to instill an antimicrobial lock solution into the lumen(s) of the catheter (lock solution) in order to prevent intraluminal colonization and the development of biofilm. Another approach is to use catheter locks containing an antibiotic. Decreased bacteremia has been reported using gentamicin and minocycline, and confirmed using meta-analysis [13-15]. However, risks include toxicity from leakage of the antibiotic into the circulation and the development of antibiotic resistance [16].

Taurolidine-citrate may be an excellent alternative. Taurolidine, a derivative of the amino acid taurine, is a potent biocompatible antimicrobial agent with broadspectrum bactericidal activity [17-19]. In vitro taurolidine yields methylol-taurinamide components that bind to bacterial and fungal cell walls, causing irreversible damage [20]. Experiments have demonstrated its efficacy in eradicating catheter biofilm caused by a variety of Gram-positive and Gram-negative bacteria, as well as Candida albicans [21]. Resistance has not been reported because the mode of action resembles a disinfectant, rather than an antibiotic [22]. Moreover, preliminary observations of patients in whom a subcutaneous dialysis device or intravenous catheter is used for hemodialysis suggest that instillation of taurolidine into the catheter lumens may prevent CRB $[6,23,24]$. However, other studies have shown that it was associated with a greater need for thrombolysis to maintain catheter patency [11, 23]. Thus, a systematic review is needed to account for this controversy. In this study, we aim to perform a systematic review and meta-analysis to estimate the pooled effectiveness and safety of taurolidine-citrate locks in comparison with standard-treatment heparin locks with regard to CRB rate and thrombosis rate using intravascular catheters.

\section{Methods}

Literature Search and Study Selection

We conducted a systematic literature search of the major English (PubMed, EBSCO, Web of Science and OVID) and Chinese [CBM, CNKI, VIP (a full-text database of Chinese journals) and
Wanfang Data] healthcare databases between January and February 2013. Search terms included 'catheter-related infections', 'heparin', 'taurolidine', 'citrate', and 'lock solutions'. References were manually inspected and relevant articles obtained.

We selected randomized controlled trials (RCTs) comparing a taurolidine-citrate lock solution (TCLS) to a standard heparin lock solution in CRB prevention. In this study, RCTs were identified by title, key words, abstract and full text with two reviewers working independently to determine which studies meet the criteria for inclusion before reaching a final consensus on which studies to include. Discrepancies would have been reviewed by the senior author. Where key information was missing from the published version, the lead author was contacted and information requested.

\section{Inclusion Criteria}

To be included in the meta-analysis, a study had to meet the following criteria: a randomized trial comparing TCLS (1.35\% taurolidine and $4 \%$ citrate) with standard heparin lock solution $(5,000$ $\mathrm{U} / \mathrm{ml}$ ), report the incidence of CRB as a principal outcome with sufficient information to allow the calculation of relative risk (RR), and use a clear definition of $\mathrm{CRB}$ and detail the procedure followed in case CRB was suspected.

\section{Data Extraction}

After the final selection, two reviewers extracted data independently. In case of discrepancies between the two raters, disagreements were solved by consultation with the senior author. Consensus was achieved after discussion.

Data concerning size of the study sample, characteristics of patient population, type of catheters and type of $\mathrm{CRB}$ pathogen (Gram-positive/Gram-negative) were extracted. Randomization and blinding procedures were also evaluated.

\section{Data Analysis}

Data analysis was performed using the inverse variance fixedeffect model for generic inverse variance data. Appropriate results from individual studies were quantitatively pooled in meta-analyses using fixed- or random-effects models, depending on heterogeneity. Heterogeneity was assessed with an $\mathrm{I}^{2}$ statistic, where $0 \%$ indicates no heterogeneity and $100 \%$ indicates the highest level of heterogeneity. If $\mathrm{I}^{2}$ was $<50 \%$, the fixed-effects model was used, and if $\mathrm{I}^{2}$ was $>50 \%$, the random-effects model was applied $[25,26]$. Effect sizes were measured primarily in mean rate difference (MRD) and secondarily in RR. Effect size measure was used to increase validity of our analysis. The MRD of CRB was calculated as CRB incidence control - CRB incidence experimental. RR of CRB was calculated as the natural logarithm (CRB incidence experimental/CRB incidence control). Pooled MRDs were estimated based on the average rate per 1,000 catheter days. Data analysis was performed using Cochrane Database's Review Manager 5.2.0 software.

\section{Results}

\section{Search Results}

A total of 58 references were retrieved from the systematic search (fig. 1). Forty studies were excluded based on the title and abstract. The other 15 studies were ex- 
Fig. 1. Flow diagram followed for the selection process of studies included in the meta-analysis.

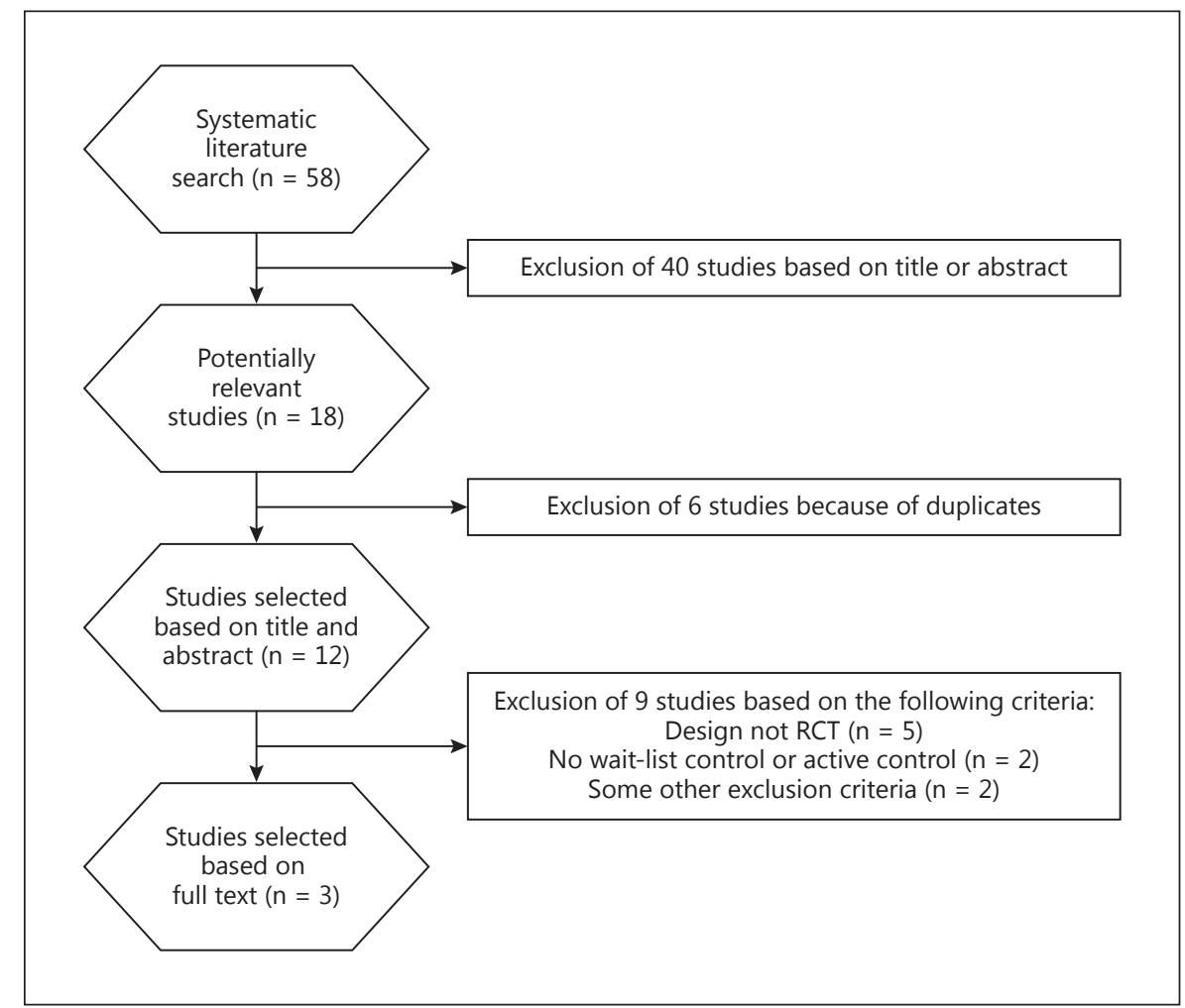

Table 1. Characteristics of the included studies

\begin{tabular}{|c|c|c|c|c|c|c|c|c|}
\hline Study & Design & Period & $\begin{array}{l}\text { Sample } \\
\text { size, } n\end{array}$ & $\begin{array}{l}\text { Age at heparin, } \\
\text { years }\end{array}$ & $\begin{array}{l}\text { Age at TCLS, } \\
\text { years }\end{array}$ & $\begin{array}{l}\text { Primary } \\
\text { endpoint }\end{array}$ & Secondary endpoint & Catheter type \\
\hline $\begin{array}{l}\text { Betjes and van } \\
\text { Agteren [27] }\end{array}$ & $\begin{array}{l}\text { randomized } \\
\text { prospective } \\
\text { trial }\end{array}$ & $\begin{array}{l}\text { May } 2002 \text { to } \\
\text { June } 2003\end{array}$ & 58 & $50.3 \pm 20.4$ & $58.3 \pm 16.3$ & $\begin{array}{l}\text { catheter- } \\
\text { related sepsis }\end{array}$ & $\begin{array}{l}\text { bacteremic episodes } \\
\text { Gram-positive and } \\
\text { Gram-negative infection }\end{array}$ & $\begin{array}{l}\text { tunneled catheter } \\
\text { and nontunneled } \\
\text { catheter }\end{array}$ \\
\hline $\begin{array}{l}\text { Solomon } \\
\text { et al. [29] }\end{array}$ & $\begin{array}{l}\text { double-blind } \\
\text { RCT }\end{array}$ & $\begin{array}{l}\text { Nov. } 2006 \text { to } \\
\text { May } 2008\end{array}$ & 110 & $56.7 \pm 17.4$ & $59.8 \pm 14.7$ & $\begin{array}{l}\text { time to first } \\
\text { bacteremia } \\
\text { event }\end{array}$ & $\begin{array}{l}\text { bacterial colonization of } \\
\text { the catheter }\end{array}$ & $\begin{array}{l}\text { tunneled cuffed } \\
\text { intravascular } \\
\text { catheters }\end{array}$ \\
\hline $\begin{array}{l}\text { Dumichen } \\
\text { et al. [28] }\end{array}$ & $\begin{array}{l}\text { randomized } \\
\text { prospective } \\
\text { trial }\end{array}$ & $\begin{array}{l}\text { Jan. } 2007 \text { to } \\
\text { Dec. } 31,2008\end{array}$ & 71 & $\begin{array}{l}\text { median: } 6.3 \\
\text { mean: } 7.9 \\
\text { (range: } 1.7-17.1 \text { ) }\end{array}$ & $\begin{array}{l}\text { median: } 7.5 \\
\text { mean: } 8.5 \\
\text { (range: } 1.4-18 \text { ) }\end{array}$ & $\begin{array}{l}\text { bacterial } \\
\text { colonization } \\
\text { of } \mathrm{CVC}\end{array}$ & $\begin{array}{l}\text { bloodstream infections, } \\
\text { thrombotic occlusions }\end{array}$ & not reported \\
\hline
\end{tabular}

$\mathrm{CVC}=$ Central venous catheter.

cluded because of duplicates $(n=6)$ or due to a nonrandomized controlled study design $(n=7)$ or based on some other exclusion criteria $(n=2)$. Thus, a total of 3 studies including 236 patients with a total of 34,984 catheter days were available for analysis [27-29]. The characteristics of the included RCTs are shown in table 1.

All 3 studies included patients with long-term catheters. Two studies included adult hemodialysis patients $[27,29]$, one studied pediatric patients with hematologi-

Preventing Catheter-Related Bacteremia with TCLS cal malignancies and catheters used for chemotherapy and intravenous medication/alimentation [28]. The inclusion and exclusion criteria for each study are shown in table 2.

Concerning randomization procedures, one study used computer-generated randomization and all study personnel and participants were blinded to treatment assignment throughout the study until the database was complete [29]. The other 2 studies did not provide de- 
Table 2. Inclusion and exclusion criteria in each study

\begin{tabular}{lll}
\hline Study & Inclusion criteria & Exclusion criteria \\
$\begin{array}{l}\text { Betjes and van } \\
\text { Agteren [27] }\end{array}$ & $\begin{array}{l}\text { patients were eligible for the study if they needed a } \\
\text { hemodialysis catheter for starting or continuing } \\
\text { hemodialysis treatment }\end{array}$ & $\begin{array}{l}\text { patients were excluded if the dialysis catheter was used in } \\
\text { the ICU or for reasons other than hemodialysis; patients } \\
\text { using antibiotics were also excluded }\end{array}$ \\
\hline $\begin{array}{lll}\text { Solomon et al. } \\
{[29]}\end{array}$ & $\begin{array}{l}\text { adult patients aged }>18 \text { years receiving tunneled } \\
\text { intravascular catheters for hemodialysis and able to } \\
\text { give informed consent }\end{array}$ & not reported \\
\hline $\begin{array}{l}\text { Dumichen et al. } \\
{[28]}\end{array}$ & $\begin{array}{l}\text { patients aged 1-18 years undergoing treatment with } \\
\text { CV placement with an expected duration of }\end{array}$ & $\begin{array}{l}\text { lack of informed consent, presence of bacteremia/sepsis at } \\
\text { screening, presence of a secondary CVC, and known allergy } \\
\text { to heparin or taurolidine-citrate. }\end{array}$ \\
\hline
\end{tabular}

$\mathrm{CVC}=$ Central venous catheter.

Table 3. The number of CRB, catheters, catheter days and thrombosis cases

\begin{tabular}{|c|c|c|c|c|c|}
\hline Study & $\begin{array}{l}\text { Lock } \\
\text { solution }\end{array}$ & $\begin{array}{l}\text { Catheters, } \\
\mathrm{n}\end{array}$ & $\begin{array}{l}\text { Catheter } \\
\text { days, } \mathrm{n}\end{array}$ & $\mathrm{CRB}, \mathrm{n}$ & $\begin{array}{l}\text { Throm- } \\
\text { bosis, } n\end{array}$ \\
\hline Betjes and van & HLS & 39 & 1,885 & 4 & 2 \\
\hline Agteren [27] & TCLS & 37 & 1,519 & 0 & 1 \\
\hline Solomon & HLS & 58 & 9,642 & 23 & 14 \\
\hline et al. [29] & TCLS & 56 & 8,129 & 11 & 28 \\
\hline \multirow{2}{*}{$\begin{array}{l}\text { Dumichen } \\
\text { et al. [28] }\end{array}$} & HLS & NR & 7,233 & 9 & 2 \\
\hline & TCLS & NR & 6,576 & 2 & 3 \\
\hline
\end{tabular}

HLS $=$ Heparin lock solution; NR = not reported.

tailed information about the method used to generate the random allocation sequence $[27,28]$.

Some additional techniques for preventing catheterrelated infections were used. In one study, an additional nasal mupirocin was used for prevention of catheter-related infections [27]. In another study, all patients routinely received cotrimoxazole for the prevention of $\mathrm{Pneu}$ mocystis jiroveci pneumonia [28]. The last study did not use any antibiotics [29].

Not all studies used the same type of catheter. Two of the 3 studies only used tunneled catheters [28, 29], while the other [27] included both tunneled catheter and nontunneled catheters.

Exit-site care is of crucial importance to patients using intravascular catheters. Only one study described exitsite care procedures [27]. Preparation and instillation of the lock solution were detailed in only 2 trials $[27,29]$.
The criteria used for CRB diagnosis in each study were as follows: a positive bacterial blood culture drawn from the catheter with no other apparent source of infection in a symptomatic patient [27], or the decision to obtain blood cultures was based on symptoms of infection such as fever (temperature $>37.5^{\circ} \mathrm{C}$ ) or rigors associated with dialysis. A single positive blood culture bottle defined a bacteremic episode. If the same organism was isolated in cultures $<3$ weeks apart, it was considered the same infection. When different organisms were identified or if cultures were $>3$ weeks apart, these were considered separate episodes [29]. A primary CRB had to meet the following criteria: the patient has a recognized pathogen cultured from one or more blood cultures, and the organism cultured from blood is not related to an infection at another site [28]. Thus, the common criteria used for CRB diagnosis in the 3 studies was a positive bacterial blood culture drawn from the catheter without any other source of infection. However, the definition of a bacteremic episode differed slightly and the criteria of Solomon's study were stricter because the possibility of recurrent infections of the same bacteria was ruled out.

All trials evaluated the incidence of exit-site infection and some of them assessed the incidence of colonization. All trials reported catheter days, CRB episodes and thrombosis, and all the studies but one [28] reported the number of catheters (table 3).

Not all papers reported the microbiology of CRB; of those that did, $66 \%(n=38)$ of the CRB cases were caused by Gram-positive organisms ( $45 \%$ were caused by $S$. aureus and $21 \%$ caused by other Gram-positive organisms) and $34 \%(n=38)$ were caused by Gram-negative organisms. Three patients reported on in the study by Solomon 
Table 4. The microbiology of CRB, CRB incidence and thrombosis rate

\begin{tabular}{|c|c|c|c|c|c|c|}
\hline \multirow[t]{2}{*}{ Study } & \multirow[t]{2}{*}{ Groups } & \multicolumn{2}{|c|}{ Gram-positive } & \multirow{2}{*}{$\begin{array}{l}\text { Gram- } \\
\text { negative }\end{array}$} & \multirow{2}{*}{$\begin{array}{l}\text { CRB incidence } \\
\text { (episodes per } \\
1,000 \text { catheter days) }\end{array}$} & \multirow{2}{*}{$\begin{array}{l}\text { Thrombosis rate } \\
\text { (episodes per } 1,000 \\
\text { catheter days) }\end{array}$} \\
\hline & & S. aureus & other & & & \\
\hline \multirow{2}{*}{$\begin{array}{l}\text { Betjes and van } \\
\text { Agteren [27] }\end{array}$} & TCLS & 0 & 0 & 0 & $0(0.5)$ & 0.66 \\
\hline & HLS & 3 & 1 & 0 & 2.12 & 1.06 \\
\hline \multirow{2}{*}{$\begin{array}{l}\text { Solomon et al. } \\
\text { [29] }\end{array}$} & TCLS & 6 & 3 & 2 & 1.35 & 3.44 \\
\hline & HLS & 8 & 4 & 11 & 2.39 & 1.45 \\
\hline \multirow{2}{*}{$\begin{array}{l}\text { Dumichen } \\
\text { et al. [28] }\end{array}$} & TCLS & NR & NR & NR & 0.21 & 0.46 \\
\hline & HLS & NR & NR & NR & 1.24 & 0.28 \\
\hline
\end{tabular}

In order to make possible the calculation of the natural logarithm (CRB experimental/CRB control), the 0 incidence reported in the studies was arbitrarily transformed to 0.5 . NR $=$ Not reported.

et al. [29] had methicillin-resistant S. aureus in CRB. Multidrug-resistant Gram-negatives and fungal infections were not reported. The microbiology of CRB is detailed in table 4.

\section{Overall Effect}

Individual and pooled results are presented in figures 2-4. The incidence of CRB and thrombosis rate in all arms of each trial are listed in table 4 .

The overall summary RR using the fixed-effects model was 0.47 (95\% CI: 0.25-0.89), indicating a significantly reduced risk of $\mathrm{CRB}$ in patients randomized to receive TCLS (fig. 2.1). The meta-analysis revealed the MRD of CRB is 1.12 (95\% CI: 0.45-1.8) (fig. 2.2). No difference was observed in Gram-positive infection (fig. 2.3), and its RR was 0.81 (95\% CI: 0.35-1.84). The overall summary risk ratio for the Gram-negative bacterial infection rate was 0.22 (95\% CI: $0.05-0.99$ ), which pointed to a strong protective impact of TCLS (fig. 2.4).

There was a significant adverse effect of taurolidinecitrate with respect to the incidence of thrombosis (fig. 3); the pooled RR against taurolidine-citrate was 2.10 (95\% CI: $1.16-3.78)$.

Figure 4 shows that the pooled RR of the exit-site infection rate, the overall summary RR using the fixed-effects model, was 1.03 (95\% CI: 0.51-2.09), indicating that there was no difference between TCLS and heparin lock solution in exit-site infection.

\section{Adverse Events}

No serious adverse events related to the TCLS were reported in any of the 3 included trials. Only Dumichen et al. [28] reported some adverse events; the recorded symptoms were discomfort in the chest and neck, perioral dysaesthesia, abnormal taste sensations, nausea and vomiting. There were no adverse events or side effects reported in the study by Betjes and van Agteren [27], and Solomon et al. [29] did not report information on side effects.

\section{Discussion}

Different types of antimicrobial agents have been investigated to prevent $\mathrm{CRB}$, and taurolidine-citrate may be an excellent agent. Our analysis showed that TCLS significantly reduced the risks of CRB and Gram-negative infections, but there was a greater need for thrombolytic therapy compared to heparin catheter locks.

Given that CRB is associated with high morbidity, mortality and cost in patients using intravascular catheters, the use of TCLS may offer a promising way to prevent this complication. It has been reported that the use of a taurolidine-citrate locking agent in patients using intravascular catheters has significantly reduced the sepsis rate and exerted positive impact on morbidity, mortality and cost [30]. In the USA, approximately 80,000 CRBs occur in ICUs each year [31]. The attributable cost per infection is an estimated USD 34,508-56,000 [32] and the annual cost of caring for patients with CRBs ranges from USD 296 million to 2.3 billion [31, 33]. The introduction of the taurolidine-citrate locks reduced the total costs of line infections in 6 months by EUR 19,200 (GBP 15,000) [30]. Though most studies reported 4-6 episodes per 1,000 catheter days [13], the incidence of CRB involved in our meta-analysis ranged from 0 to 2.39 episodes per 1,000 catheter days (table 4), and the meta-analysis indi- 


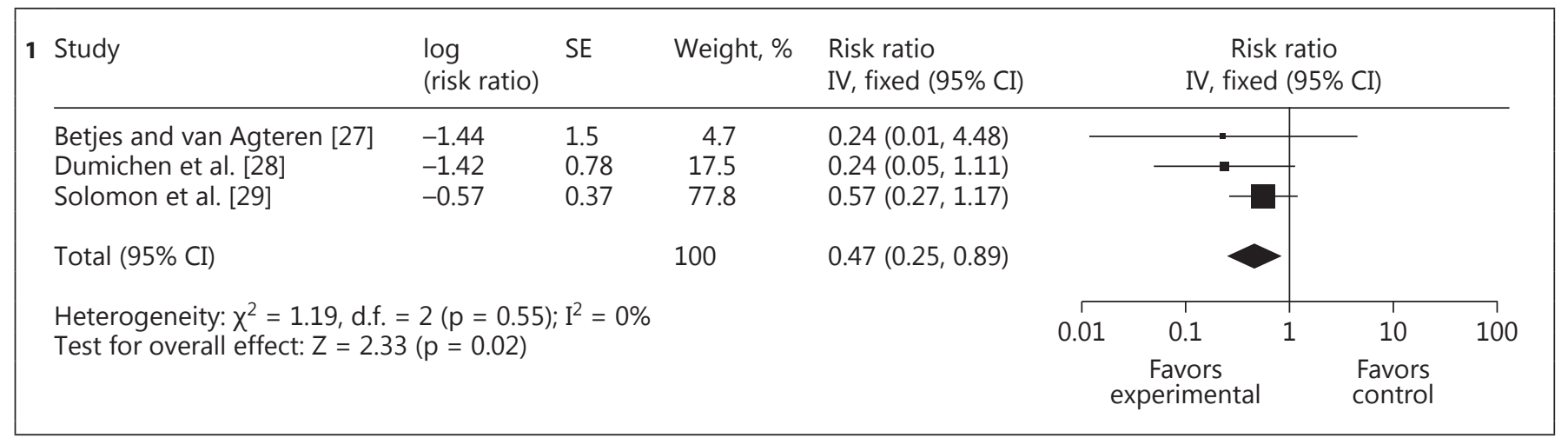

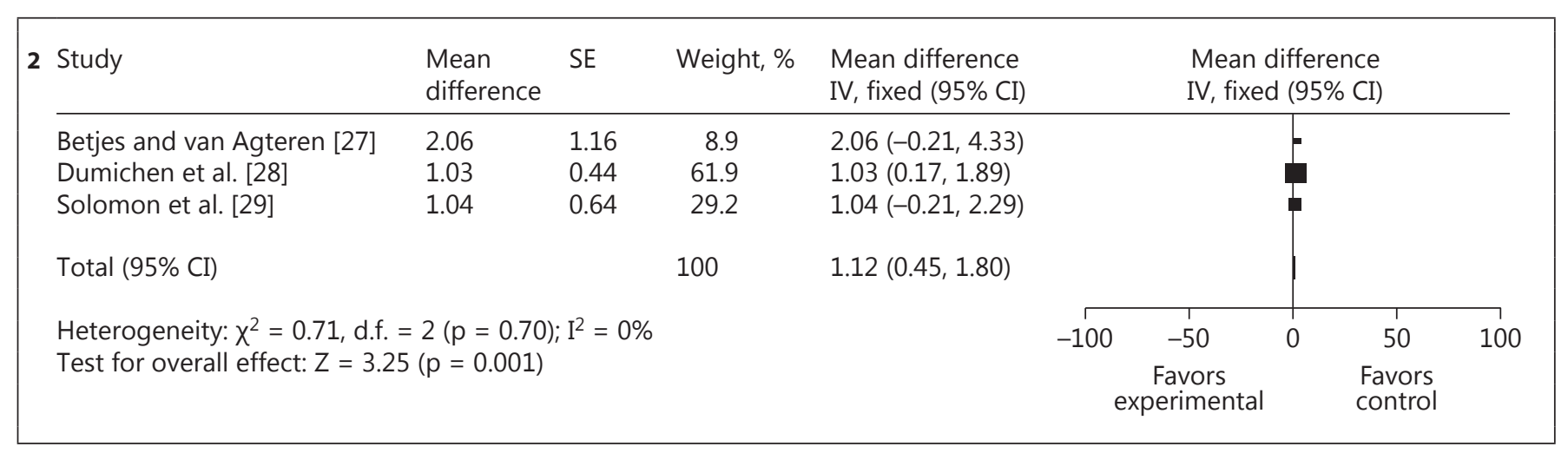

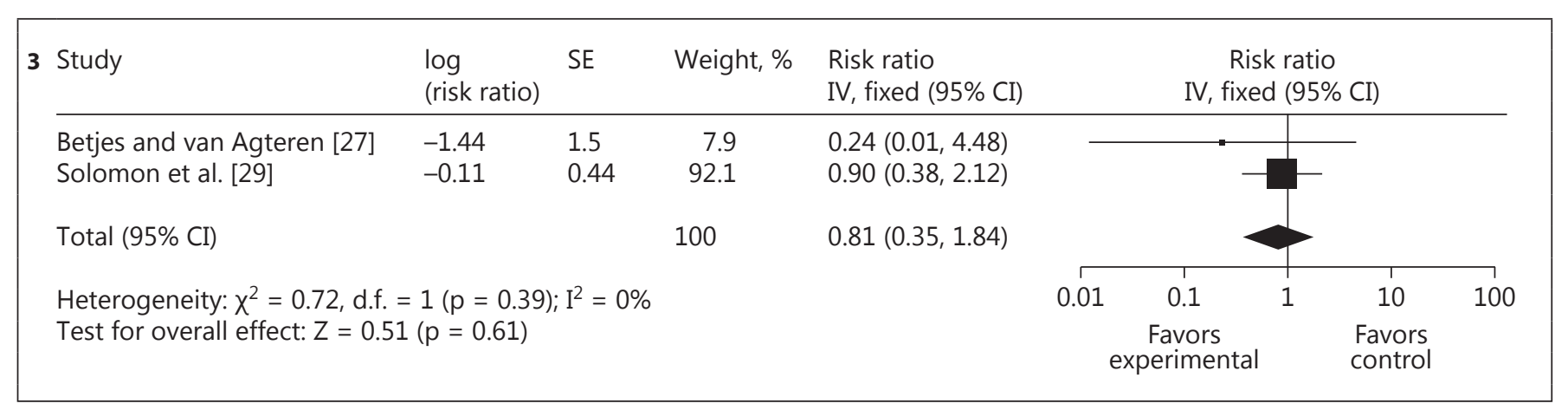

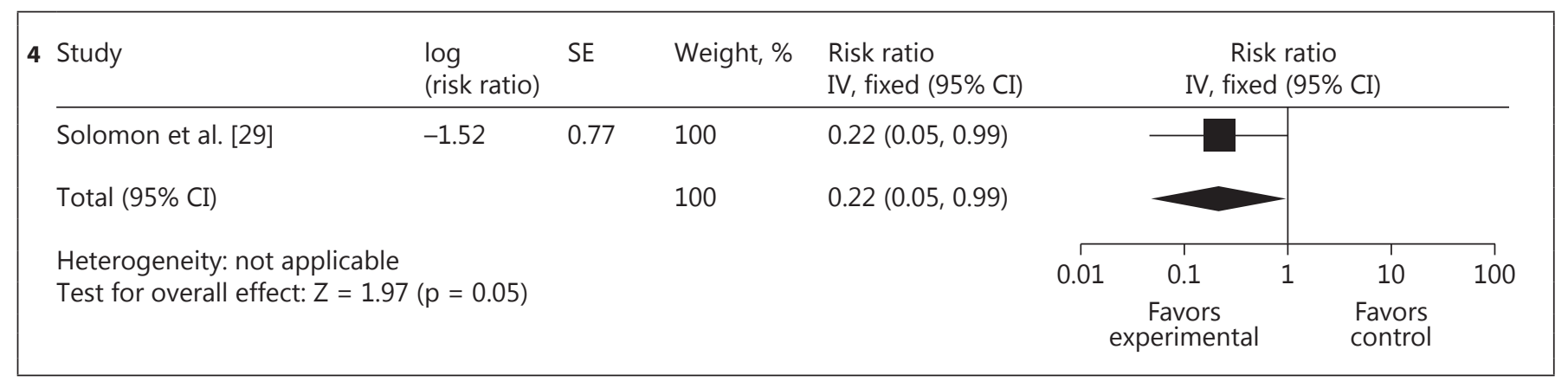

Fig. 2. Pooled RR of CRB rate and its bacterial infection rate. 1 Pooled RR of CRB rate. 2 MRD of CRB. 3 Pooled RR of the Gram-positive bacterial infection rate. 4 Pooled RR of the Gram-negative bacterial infection rate. 


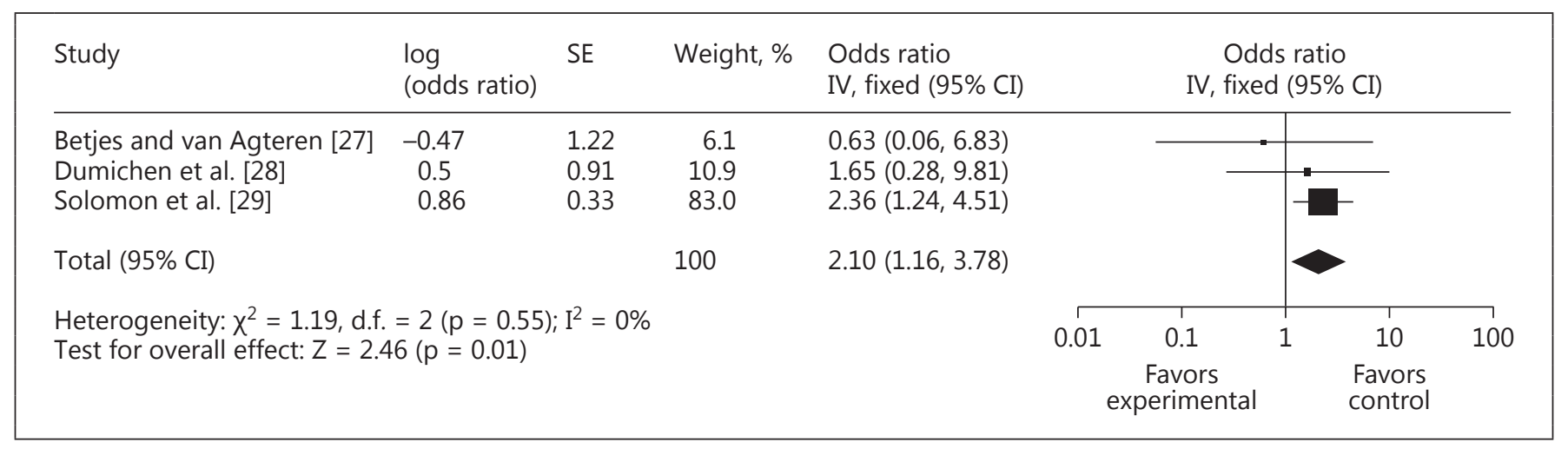

Fig. 3. Pooled RR of the thrombosis rate.

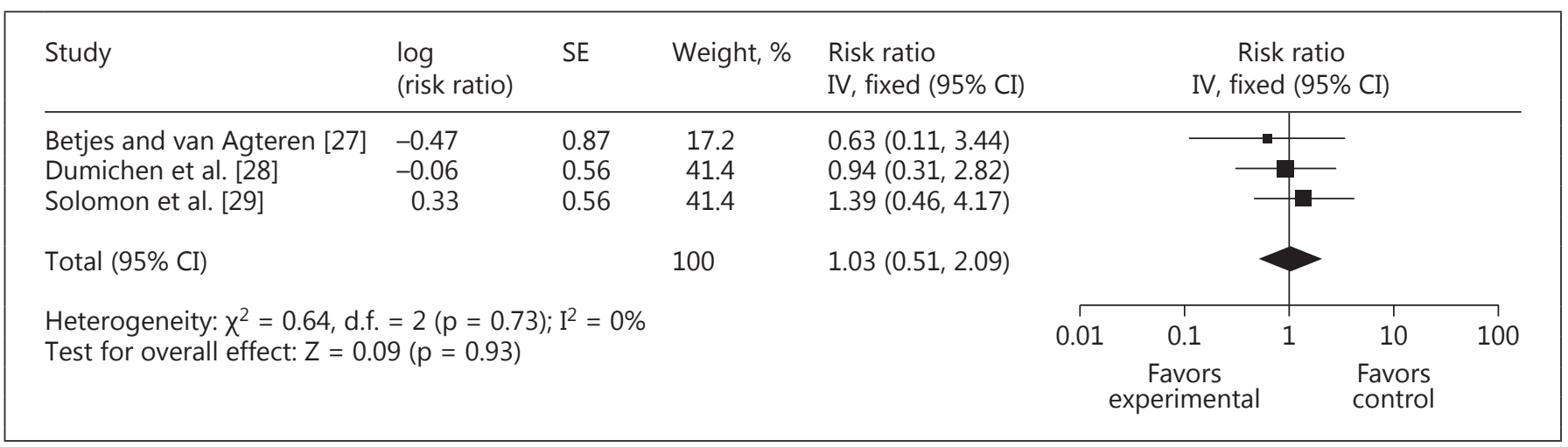

Fig. 4. Pooled RR of the exit-site infection rate.

cated that the use of TCLS decreased the risk of CRB by approximately a factor of 1.12 episodes per 1,000 catheter days (fig. 2.2).

The main disadvantage of taurolidine-citrate was a greater need for thrombolytic therapy to maintain catheter patency, indicating a less effective anticoagulant activity of $4 \%$ sodium citrate compared with heparin. Observational evidence suggested that the addition of a small amount of heparin solved this problem [11]. A further study to determine the optimum amount of heparin is needed.

Formation of an intraluminal microbial biofilm has been noted to play a significant role in the development of catheter-related infections [34]. Microbial colonization and development of biofilms, which are known to be recalcitrant to antibiotic therapy, often lead to the loss of vascular access system patency. The use of catheter lock solutions has been recognized as an effective way to pre-

Preventing Catheter-Related Bacteremia with TCLS vent CRB, probably by reducing biofilm formation [20]. However, one study included in our meta-analysis [29] only found accumulation of fibrin, erythrocytes and platelets at the tip of all catheters in both groups using transmission electron microscopy; they failed to manifest bacterial biofilms in any catheter. However, other studies have revealed that most central vein catheters develop a bacterial biofilm on their inner surface as early as $24 \mathrm{~h}$ after their placement $[35,36]$. Therefore, it may be hard to determine whether taurolidine-citrate destroys established bacterial biofilm or not. Although host factors such as humoral, cellular response and leukocyte function are important defense mechanisms against CRB, a taurolidine-citrate-heparin lock solution has effectively eradicated pathogens from the catheter biofilm in hemodialysis patients [37]. Therefore, larger in vivo studies are needed to explore the association between biofilm formation and CRB. 
There was no significant difference in the incidence of Gram-positive organisms including S. aureus in our meta-analysis. Most of organisms isolated from patients in 3 trials [27-29] were S. aureus. In vitro studies have indicated that the concentration of taurolidine was sufficient to kill $S$. aureus $[21,38]$. One possibility is that $S$. aureus enters by a different portal, such as the exit site. It is said that TCLS significantly reduced central venous access device-associated Gram-positive infections (coagulase-negative staphylococci and methicillin-resistant $S$. epidermidis) in pediatric cancer patients [10]. This point might need further study. However, it is proven to significantly reduce risk of Gram-negative infections in patients randomized to receive TCLS. Likewise, a recent study observed similar results $[22,23]$.

Exit-site infections may also contribute to the pathogenesis of CRB [39]. In studies included in our meta-analysis, a low incidence of exit-site infections was observed with, as expected, no difference between the heparin- and citrate-taurolidine-filling groups, indicating that exit-site infections may have a different pathogenesis. Optimal catheter care by an experienced nursing team reduced the rate of CRB by up to 8 times [39], which implies meticulous nursing techniques might be of particular importance. We were unable to display a difference in bacterial colonization incidence for catheters filled with taurolidine-citrate or heparin. Bacterial infections related to catheters can develop through extra- and intraluminal routes [40]. This may require different measures.

\section{Conclusions}

Our analysis indicated that catheter locking with taurolidine-citrate reduced the incidence of CRB and Gramnegative bacterial infection, whereas it was associated with an increased need for thrombolysis. We believe TCLS would be preferable to heparin or antibiotic locks if the need for thrombolysis can be decreased.

\section{Limitations}

Some possible limitations of this meta-analysis have to be considered in explaining the results. Firstly, publication bias may have occurred because only published researches were included in this study. A funnel plot was not performed to assess the publication bias because there were only 3 studies in this meta-analysis. Secondly, as with other meta-analyses, limitations come from heterogeneity of the study populations, protocols and outcome definitions. Thus, in the future, more RCTs are needed to confirm these results.

\section{Acknowledgements}

This research was supported by the Natural Science Foundation of Hunan Province, China (No. 12JJ3092 and 14JJ7015; http:// www.hnst.gov.cn/zxgz/zkjj/).

\section{Disclosure Statement}

The authors certify that no conflict of interest exists.

\section{References}

1 Castagnola E, Ginocchio F: Rescue therapy of difficult-to-treat indwelling central venous catheter-related bacteremias in cancer patients: a review for practical purposes. Expert Rev Anti Infect Ther 2013;11:179-186.

2 Li S, Bizzarro MJ: Prevention of central line associated bloodstream infections in critical care units. Curr Opin Pediatr 2010;23:85-90.

$\checkmark 3$ Bradshaw JH, Puntis JW: Taurolidine and catheter-related bloodstream infection: a systematic review of the literature. J Pediatr Gastroenterol Nutr 2008;47:179-186.

4 Opilla M: Epidemiology of bloodstream infection associated with parenteral nutrition. Am J Infect Control 2008;36:S173.e5-e8.

-5 Santarpia L, Pasanisi F, Alfonsi L, Violante G, Tiseo D, De Simone G, Contaldo F: Prevention and treatment of implanted central venous catheter $(\mathrm{CVCH})$-related sepsis: a report after six years of home parenteral nutrition (HPN). Clin Nutr 2002;21:207-211.

-6 Jurewitsch B, Jeejeebhoy KN: Taurolidine lock: The key to prevention of recurrent catheter-related bloodstream infections. Clin Nutr 2005;24:462-465.

7 Weber DJ, Rutala WA: Central line-associated bloodstream infections: prevention and management. Infect Dis Clin North Am 2011; 25:77-102.

-8 Al-Amin AH, Sarveswaran J, Wood JM, Burke DA, Donnellan CF: Efficacy of taurolidine on the prevention of catheter-related bloodstream infections in patients on home parenteral nutrition. J Vasc Access 2013;14:379-382.

9 Rabe C, Gramann T, Sons X, Berna M, Gonzalez-Carmona MA, Klehr HU, Sauerbruch T, Caselmann WH: Keeping central venous lines open: a prospective comparison of hepa- rin, vitamin $\mathrm{C}$ and sodium chloride sealing solutions in medical patients. Intensive Care Med 2002;28:1172-1176.

10 Simon A, Ammann RA, Wiszniewsky G, Bode U, Fleischhack G, Besuden MM: Taurolidine-citrate lock solution (TauroLock) significantly reduces CVAD-associated grampositive infections in pediatric cancer patients. BMC Infect Dis 2008;8:102.

11 Solomon LR, Cheesbrough JS, Bhargava R, Mitsides N, Heap M, Green G, Diggle P: Observational study of need for thrombolytic therapy and incidence of bacteremia using taurolidinecitrate-heparin, taurolidine-citrate and heparin catheter locks in patients treated with hemodialysis. Semin Dial 2011;25:233-238.

12 Mandolfo S: Central venous catheter lock to prevent thrombosis and bacterial infection (in Italian). G Ital Nefrol 2012;29:301-307. 
13 Labriola L, Crott R, Jadoul M: Preventing haemodialysis catheter-related bacteraemia with an antimicrobial lock solution: a meta-analysis of prospective randomized trials. Nephrol Dial Transplant 2008;23:1666-1672.

14 Silva TN, Mendes ML, Abrao JM, Caramori JT, Ponce D: Successful prevention of tunneled central catheter infection by antibiotic lock therapy using cefazolin and gentamicin. Int Urol Nephrol 2013;45:1405-1413.

15 Weber JM, Sheridan RL, Fagan S, Ryan CM, Pasternack MS, Tompkins RG: Incidence of catheter-associated bloodstream infection after introduction of minocycline and rifampin antimicrobial-coated catheters in a pediatric burn population. J Burn Care Res;33:539543.

16 Landry DL, Braden GL, Gobeille SL, Haessler SD, Vaidya CK, Sweet SJ: Emergence of gentamicin-resistant bacteremia in hemodialysis patients receiving gentamicin lock catheter prophylaxis. Clin J Am Soc Nephrol 2010;5 1799-1804.

- 17 Droste JC, Jeraj HA, MacDonald A, Farrington K: Stability and in vitro efficacy of antibiotic-heparin lock solutions potentially useful for treatment of central venous catheter-related sepsis. J Antimicrob Chemother 2003;51:849-855.

18 Fratino G, Molinari AC, Parodi S, Longo S, Saracco P, Castagnola E, Haupt R: Central venous catheter-related complications in children with oncological/hematological diseases: an observational study of 418 devices. Ann Oncol 2005; 16:648-654.

19 Traub WH, Leonhard B, Bauer D: Taurolidine: In vitro activity against multiple-antibiotic-resistant, nosocomially significant clinical isolates of Staphylococcus aureus, Enterococcus faecium, and diverse Enterobacteriaceae. Chemotherapy 1993;39:322-330.

20 Handrup MM, Fuursted K, Funch P, Moller JK, Schroder H: Biofilm formation in longterm central venous catheters in children with cancer: a randomized controlled open-labelled trial of taurolidine versus heparin APMIS 2012;120:794-801.
21 Shah CB, Mittelman MW, Costerton JW, Parenteau S, Pelak M, Arsenault R, Mermel LA: Antimicrobial activity of a novel catheter lock solution. Antimicrob Agents Chemother 2002;46:1674-1679.

22 Willatts SM, Radford S, Leitermann M: Effect of the antiendotoxic agent, taurolidine, in the treatment of sepsis syndrome: a placebo-controlled, double-blind trial. Crit Care Med 1995;23:1033-1039.

23 Filiopoulos V, Hadjiyannakos D, Koutis I, Trompouki S, Micha T, Lazarou D, Vlassopoulos D: Approaches to prolong the use of uncuffed hemodialysis catheters: results of a randomized trial. Am J Nephrol 2011;33:260268.

24 Geron R, Tanchilevski O, Kristal B: Catheter lock solution - taurolock for prevention of catheter-related bacteremia in hemodialysis patients (in Hebrew). Harefuah 2006; 145: 881-884, 943

25 DerSimonian R, Kacker R: Random-effects model for meta-analysis of clinical trials: an update. Contemp Clin Trials 2007;28:105114.

26 Higgins J, Thompson S, Deeks J, Altman D: Statistical heterogeneity in systematic reviews of clinical trials: a critical appraisal of guidelines and practice. J Health Serv Res Policy 2002;7:51-61.

27 Betjes MG, van Agteren M: Prevention of dialysis catheter-related sepsis with a citratetaurolidine-containing lock solution. Nephrol Dial Transplant 2004;19:1546-1551.

28 Dumichen MJ, Seeger K, Lode HN, Kuhl JS, Ebell W, Degenhardt P, Singer M, Geffers C, Querfeld U: Randomized controlled trial of taurolidine citrate versus heparin as catheter lock solution in paediatric patients with haematological malignancies. J Hosp Infect 2012; 80:304-309.

29 Solomon LR, Cheesbrough JS, Ebah L, AlSayed T, Heap M, Millband N, Waterhouse D, Mitra S, Curry A, Saxena R, Bhat R, Schulz M, Diggle P: A randomized double-blind controlled trial of taurolidine-citrate catheter locks for the prevention of bacteremia in patients treated with hemodialysis. Am J Kidney Dis 2010;55:1060-1068.

30 Taylor C, Cahill J, Gerrish M, Little J: A new haemodialysis catheter-locking agent reduces infections in haemodialysis patients. J Ren Care 2008;34:116-120.
1 O'Grady NP, Alexander M, Dellinger EP, Gerberding JL, Heard SO, Maki DG, Masur $\mathrm{H}$, McCormick RD, Mermel LA, Pearson ML, Raad II, Randolph A, Weinstein RA: Guidelines for the prevention of intravascular catheter-related infections. Centers for disease control and prevention. MMWR Recomm Rep 2002;51:1-29.

32 Rello J, Ochagavia A, Sabanes E, Roque M, Mariscal D, Reynaga E, Valles J: Evaluation of outcome of intravenous catheter-related infections in critically ill patients. Am J Respir Crit Care Med 2000;162:1027-1030.

33 Dimick JB, Pelz RK, Consunji R, Swoboda SM, Hendrix CW, Lipsett PA: Increased resource use associated with catheter-related bloodstream infection in the surgical intensive care unit. Arch Surg 2001;136:229-234.

- 34 Singhai M, Malik A, Shahid M, Malik MA, Goyal R: A study on device-related infections with special reference to biofilm production and antibiotic resistance. J Glob Infect Dis 2013;4:193-198.

35 Donlan RM: Biofilm formation: A clinically relevant microbiological process. Clin Infect Dis 2001;33:1387-1392.

36 Ebert T, Smith S, Pancari G, Wu X, Zorman J, Clark D, Cook J, Burns C, Antonello JM, Cope L, Nagy E, Meinke A, McNeely T: Development of a rat central venous catheter model for evaluation of vaccines to prevent staphylococcus epidermidis and staphylococcus aureus early biofilms. Hum Vaccin 2011;7:630638.

37 Zwiech R, Adelt M, Chrul S: A taurolidinecitrate-heparin lock solution effectively eradicates pathogens from the catheter biofilm in hemodialysis patients. Am J Ther 2013, Epub ahead of print.

38 Torres-Viera C, Thauvin-Eliopoulos C, Souli M, DeGirolami P, Farris MG, Wennersten CB, Sofia RD, Eliopoulos GM: Activities of taurolidine in vitro and in experimental enterococcal endocarditis. Antimicrob Agents Chemother 2000;44:1720-1724.

39 Raad I: Intravascular-catheter-related infections. Lancet 1998:351:893-898.

40 Cheesbrough JS, Finch RG, Burden RP: A prospective study of the mechanisms of infection associated with hemodialysis catheters. J Infect Dis 1986;154:579-589. 